\title{
O regime de autonomia avaliativo no Sistema Nacional de Pós-Graduação e o futuro das relações entre historiografia, ensino e experiência da história
}

Valdei Lopes de Araujo*

Resumo: Neste artigo analiso como a acomodação da historiografia em um regime de autonomia marcado por modelos avaliativos metrificáveis afasta o campo de suas origens disciplinares no século XIX e do desenvolvimento profissional processado ao longo do século XX. Entendo por "regime de autonomia" o arranjo de forças históricas que possibilita um determinado discurso ganhar individualidade e diferenciar-se no tecido de enunciações disponíveis em época e lugar definidos. Um "regime" é a forma de descrevermos como a interação dessas forças afeta e configura o discurso, em especial a relação entre os vetores autor, leitor, circulação, linguagens, conceitos e médias. A hipótese aqui desenvolvida é que um "regime de autonomia avaliativo", comum a outras esferas da ciência moderna, tem transformado a historiografia e o historiador contemporâneo, celebrando um perfil de alta especialização, baixa relevância e comunicabilidade social que coloca em risco a capacidade deste profissional colaborar para a diversificação das formas de experiência histórica.

Palavras-chave: Sistema Nacional de Pós-Graduação. Historiografia. Regime de autonomia avaliativo. Ensino de História.

"Professor Associado de Teoria e História da Historiografia da Universidade Federal de Ouro Preto. Doutor em História Social da Cultura pela Pontifícia Universidade Católica do Rio de Janeiro, com estágio PDEE na Universidade de Stanford. E-mail: valdei354@gmail.com 
O regime de autonomia avaliativo no Sistema Nacional de Pós-Graduação...

\section{Introdução}

O debate promovido pela Anpuh Nacional em maio de 2015 perguntava pela relevância e funções sociais da historiografia, em especial seu papel no universo escolar'. A pergunta pela função social, recorrente em nosso campo de investigação, agora é motivada pelo (0) risco de redução ou mesmo desaparecimento do ensino de história - em bases disciplinares dos currículos de ensino fundamental e médio, bem como pelas ameaças à autonomia do trabalho docentes embutida em projetos como o "Escola Sem Partido". O louvável esforço por um ensino interdisciplinar alimenta vozes que pedem por uma simplificação dos currículos, refletindo o desejo por uma formação mais enquadrada às necessidade básicas da economia e às diretrizes globais produzidas por instituições como a Organização de Cooperação e de Desenvolvimento Econômico (OCDE), promotora do mais influente índice de avaliação educacional, o Programme for International Student Assessment (PISA). Neste artigo, gostaria de pensar como o nosso modelo atual da pós-graduação impacta na circulação e legitimidade do conhecimento em nossa área e nas humanidades em geral, como o crescimento quantitativo das pesquisas pode conviver com pressões pelo empobrecimento da experiência histórica.

O debate pela qualidade do ensino, motivado por sistemas de avaliação baseados em uma linguagem e visão de mundo que naturalizam a economia de mercado, tem levado a uma enorme redução das expectativas e missão da educação em geral, e da pública em particular. Ao consagrarem o letramento e as habilidades matemáticas como padrões únicos e universais da avaliação da qualidade do ensino básico, exames como o PISA, e mesmo o brasileiro IDEB, acabam por justificar o desinvestimento público na educação de base humanista. Em busca de melhorias de curto prazo nesses indicadores, os gestores públicos optam por concentrar os recursos e as iniciativas numa versão profundamente simplificada do que deveria ser o ensino público de qualidade. A pressão pela redução do conteúdo disciplinar nas áreas de Humanidades restringe a oferta da educação como formação a uma pequena elite global, enquanto trata como mero investimento em recursos humanos a 
educação pública de acesso universal. $\mathrm{O}$ fato de nesses exames o conhecimento histórico, dentre muitos outros, não ser objeto de mensuração, priva a sociedade de importante ferramenta para avaliar o "direito à história", legitimando o desinvestimento público. Hoje já temos diversos exemplos de pesquisas que se propõem a avaliar a consciência ou a experiência histórica (CARRETERO; ALPHEN, 2014; CERRI, 2011), mas sem oferecerem um indicador estável que pudesse subsidiar metodologias regulares. Essa ação certamente passa por um esforço de definição do que se espera do ensino e da educação em história, para além da aquisição de conteúdos ou mesmo a normalização etapista das "consciências históricas" com seu etnocêntrismo latente. Como e o quê, por exemplo, ensinar acerca do "tempo histórico", como propõe Hernández \& Paz (2013). Nessa direção, embora polêmico em diversos níveis, a iniciativa do estabelecimento de Bases Nacionais Curriculares pode ter resultados positivos ao estabelecer mais claramente os "direitos de aprendizado" em cada área de conhecimento ${ }^{2}$.

Mas tais iniciativas parecem ainda tímidas em um quadro de desinvestimento público em nome de políticas de avaliação e excelência que atinge todos os níveis de ensino e estão articulados em escala global. O Processo de Bolonha, em curso avançado de implantação na União Europeia, consagrou uma visão mercadológica e pragmática da educação a serviço do mercado e da produção de riqueza: "[...] a educação superior passa a ser considerada um serviço lucrativo e rentável e não propriamente um direito de todas as pessoas" (SILVA, 2013, p. 251). No Brasil, a transição entre as Universidades Profissionais, centrada no ensino, à Universidades de Investigação e Pesquisa, tem um ritmo semelhante ao Europeu, sensivelmente acelerado a partir dos grandes projetos de modernização nacional entre as décadas de 1960-1970.

Além dessa dimensão curricular, mais recentemente temos nos perguntado sobre a extensão e qualidade da formação em história do brasileiro médio (LEWKOWICZ; RODRIGUEZ, 2016; PIMENTA et al., 2014). A polarização do debate político nos últimos anos, a discussão motivada pela Comissão Nacional da Verdade acerca de nossa história recente e seu significado, tornaram visível um grande descompasso entre a consciência média dos profissionais 
em história, seus valores, e as interpretações e narrativas históricas de amplos setores da sociedade brasileira (PEREIRA, 2015). Essas constatações devem nos alertar para as diferenças entre a celebração de uma crescente historiografia especializada e os efeitos éticos que ela é capaz de produzir. Como destacou Benito Schmidt ao escrever sobre a memória da Ditadura:

Estes exemplos recentes - e aqui voltamos ao tema do quantitativo e do qualitativo com o qual comecei o artigo mostram que mais do que 'muita memória', precisamos de 'boa memória', que esteja entre o excesso e a falta, pois ambas escapam à crítica e tendem ou à sacralização ou à manipulação (SCHMIDT, 2015, p. 174).

Mesmo no universo de professores de história, com o papel cada vez maior da rede privada, é difícil identificar um conjunto ético ancorado em uma formação profissional com os quais possamos afirmar certo consenso em torno de valores democráticos mínimos. Para muitos, o historiador e a historiografia vêm perdendo espaço na construção da cultura histórica, seja pela crise de uma suposta transmissão escolar (que não pode ser reduzida ao problema da formação do professor), seja pela "democratização" dos usos da história ou o controle da memória social pelos grandes conglomerados mediáticos ou ainda pelo afastamento "natural" entre conhecimento especializado e interesse social.

Em artigo de 2012, o historiador mexicano Paulo Cesar León Palácios, define de forma concisa os temas que deveriam estar no centro da preocupação historiadora "[...] a difusão da história, sua recepção e o acesso às condições de possibilidade de sua produção" (PALACIOS, 2012, p. 139). No final do mesmo artigo, recorda a pergunta que motiva essa escolha temática: “[...] los medios de masas tienden a dominar el 'conocimiento' del mundo, por encima de la ciencia (y la historia), qué actitud podría tomar la historia?" (PALACIOS, 2012, p. 142). Ou, nas palavras de Carlos Barros, historiador espanhol fundador da rede história em debate: "Sin historiadores en la arena pública, la alternativa será la banalización 
de la historia como un producto más del debate ideológico y la sociedad de consumo" (BARROS, 2007).

Nas últimas décadas, o que podemos chamar de "giro historiográfico" nos tornou mais conscientes dos limites do conhecimento histórico, das grandes questões epistemológicas e éticas em torno da pesquisa e representação histórica. Esse movimento de análise critica é sinal de amadurecimento da comunidade historiadora, que já não depende exclusivamente de especialistas externos para pensar seus próprios fundamentos. Essa virada crítica deve servir para reafirmarmos, sem ingenuidades, a relevância e funções da historiografia como atividade disciplinar e a história como dimensão humana constitutiva que deve ser coletiva e individualmente realizada. Afirmar o ser humano como ser histórico significa dizer que o direito à história, para o qual a disciplina tem incessantemente contribuído, é um direito fundamental, inclusive por suas implicações éticas e a preocupação com uma historiografia de valores e voltada para a democratização (ABREU; RANGEL, 2015; BARROS, 2014). Ao lado do direito à vida, o direito à história é nossa condição humana própria. Claro que a realização desta dimensão de nossa humanidade não depende apenas de uma disciplina, mas até hoje a existência de historiografias tem sido uma das formas mais efetivas e democráticas de prover acesso ao direito fundamental à história. Quando digo direito à história quero dizer acesso às condições plenas de desenvolvimento e experiência de nossa condição humana, e não uma espécie de difusão de versões simplificadas de caráter pragmático a serviço de projetos de estados, nações, especialistas ou mercados. A afirmação da disciplina passou sempre pela consciência da dificuldade em negociar constantemente suas fronteiras frente às múltiplas pressões, afirmar que a historiografia foi apenas uma "ferramenta" dessas forças é ignorar o que ela tem de mais fundamental, a capacidade de alargar nossa experiência e conhecimento da história, de voltar-se contra si mesma, mesmo que buscando fora de suas fronteiras os recursos para fazê-lo, pois a ideia de autonomia disciplinar não é alheia à porosidade de suas fronteiras, muito antes a exige ${ }^{3}$.

A partir dos século XVIII-XIX podemos identificar o surgimento de um padrão historiográfico que precisou negociar sua 
autonomia com o Estado nacional emergente. De modo amplo, esse padrão disciplinar produziu a conjunção entre método, pesquisa com fontes primárias, autoria e originalidade, ineditismo, livro erudito e científico, despolitização, relevância social no ensino e na produção de uma memória de base "científica" e universalmente aceita. Até meados do século XX, o padrão de especialização assentado em instituições como academias e faculdades manteve de pé exigências de comunicação em linguagem literária, recusando-se a produzir uma metalinguagem científica excessivamente hermética.

Esse padrão de uma autonomia meio cientifica, meio letrada, predominou, com transformações, até a universitarização em bases contemporâneas. Em boa parte do século XX o historiador ainda pode ser enquadrado como um intelectual público, que apesar de produzir um conhecimento crescentemente especializado, precisava e interferia nos grandes debates nacionais, em particular através da mídia impressa. Esse quadro mudou aceleradamente a partir dos anos 70, com o grande crescimento das pós-graduação e a estabilização da prática historiadora em bases institucionais acadêmico-universitárias, com um processo formativo crescentemente homogêneo e estável, amplamente regulado e avaliado pelo Estado em níveis de graduação e pós-graduação, com uma carreira docente igualmente estável, regulada por concursos públicos, tanto em nível superior, quanto no ensino fundamental e médio.

Não se pode duvidar que a historiografia no Brasil viveu e vive um momento de grande expansão. Nunca tanto conhecimento histórico de grande qualidade esteve disponível como hoje. Diversos cursos de graduação e pós-graduação dão base a uma comunidade que cresceu e se qualificou nos últimos 40 anos. Esse crescimento fica evidente no aumento de cursos de graduação e pós-graduação e uma presença disciplinar até agora garantida nos sistemas de ensino fundamental e médio pelo seu papel central na formação de professores nos cursos de licenciatura. Mas a pergunta que precisamos nos fazer é quanto desse crescimento se traduziu em comunicação e relevância social? Neste texto, gostaria de analisar dois desafios ou ameaças ao crescimento da historiografia em suas bases atuais: 1. A heteronomia dos modelos científicos e de avaliação. 2. A baixa comunicação e legitimidade social do conhecimento academicamente 
produzido. Parto da hipótese que essas duas ameaças têm a mesma origem, o modelo de avaliação da produção historiográfica consolidado nos últimos 40 anos e um processo de reforma educacional que aposta não na formação plena do ser humano, mas na sua conformação periférica à economia global.

\section{A formação do Sistema Nacional de Pós-Graduação: uma leitura crítica dos PNPGs}

O I Plano Nacional de Pós-Graduação (PNPG) foi produzido para o período 1975 e 1979. Nela se identificava a fragilidade da pós-graduação no Brasil e previa, entre suas diretrizes, a institucionalização de um sistema nacional para "[...] elevar os seus atuais padrões de desempenho e racionalizar a utilização dos recursos, aumentando o rendimento e a produtividade dos processos de trabalho, assegurando a melhor qualidade possível dos cursos" (BRASIL, 1974, p. 126). A concepção do Sistema Nacional de Pós- Graduação (SNPG) visava reduzir a diversidade e instabilidade da oferta, concentrando no MEC todas as atribuições de gestão e controle dos cursos, em um processo que reduziria a autonomia universitária nesse âmbito.

O segundo plano, de 1981, é um documento mais frágil e sumário do que o primeiro, insiste na necessidade de criação de ferramentas de "mensuração da qualidade", mas reconhece a complexidade do processo, não "isento de controvérsia" (BRASIL, 1981, p. 187). Chama a atenção que seria "[...] preciso que as universidades e instituições de pós-graduação proced[essem] periodicamente a uma avaliação crítica do seu desempenho e de sua própria produtividade" (BRASIL, 1981, p. 187). Na prática, essa avaliação interna nunca chegou a ser regulamentada, as avaliações externas da Capes se tornaram a única forma efetiva de acompanhamento das pós-graduações, tendo um enorme efeito indutor na configuração dos campos de conhecimento ${ }^{4}$.

O terceiro PNPG foi produzido entre 1986 e 1989, é o primeiro após a redemocratização. Um dado destacado foi o aumento de docentes em regime integral como marco da política iniciada em 
O regime de autonomia avaliativo no Sistema Nacional de Pós-Graduação...

1975-1976. Esse antigo “intelectual”, agora cada vez mais ligado ao Sistema de Pós-Graduação, vai se tornando um funcionário público em tempo integral, com forte pressão sobre a avaliação de suas atividades. $\mathrm{O}$ relatório destaca, não por acaso, o papel decisivo da implantação e a consolidação do Sistema de Acompanhamento e Avaliação da Pós-Graduação, sob a responsabilidade da CAPES (BRASIL, 1985, p. 193).

O III PNPG estabelece a universidade como o ambiente privilegiado para a produção e criação do conhecimento, através da pesquisa e da pós-graduação, enfatizando o seu papel no processo de desenvolvimento nacional, entendida como dependente do "[...] estoque disponível de recursos humanos com qualificação adequada às atividades de ciência e tecnologia”. Se em 1975 eram 370 programas de mestrado e 89 de doutorado, em 1985 já haviam 787 mestrados e 325 de doutorado, um crescimento de mais de 200\% em uma década (BRASIL, 1985, p. 196).

Em 1985 o tempo médio para formação de um mestre era de 5 anos e de um doutor 5,5 anos (BRASIL, 1985, p. 197). Embora pareçam longos se comparados aos prazos atuais, esses números já representavam uma sensível melhora na produtividade dos programas. O Plano afirma a pós-graduação como indissociável da pesquisa, com uma definição de pesquisa bastante atrelada à ideia de desenvolvimento tecnológico. $\mathrm{O}$ conceito de pesquisa torna-se então o centro da pós-graduação, substituindo o de formação de pessoal superior, que até então parecia predominar, quando o foco era a reprodução de quadros para a expansão universitária. Esse deslocamento seria particularmente problemático para as Humanidades, pois seriam forçadas a traduzir seus procedimentos, até então centrados na ideia de formação, ao vocabulário das ciências duras $^{5}$. O efeito mais visível desse deslocamento, além dos encurtamentos de prazo e do subfinanciamento, foi a importância cada vez maior do artigo em periódico na avaliação dos programas e a ênfase na produção de conhecimento novo em detrimento da transmissão e formação.

O IV PNPG, previsto para 1996-1997, não chegou a ser elaborado, apesar dos debates e seminários realizados para este fim (BRASIL, 2004, p. 17-18). Ele só viria a ser retomado entre 2003 e 
2004. Naquele momento pôde-se celebrar a Capes como "[...] tendo, em relação a todos os programas e aos cursos de pós-graduação stricto sensu, o papel de assegurar a validade nacional dos diplomas" (BRASIL, 2004, p. 23). O que significou igualmente uma redução da autonomia das universidades na criação e avaliação de seus cursos. Os 325 doutorados registrados em 1985 agora chegavam a 1.034, cerca de 320\% de crescimento em duas décadas (BRASIL, 2004, p. 28). Em 1987 havia quase 8 mil alunos matriculados em cursos de doutorado, em 2003 eram mais de 40 mil, um incremento de cerca de 415\% em 16 anos. É clara a opção pelo crescimento acelerado e a pressão pelo aumento de produtividade, com incremento do número de alunos e a redução do período de formação. Já o número de docentes envolvidos com pós-graduação cresceu de 13.349 em 1987 para 32.354 em 2003, um crescimento de "apenas" 140\%. É evidente que houve um enorme ganho de produtividade na relação aluno-professor, que parece continuar na última década, embora teríamos que considerar os impactos da expansão promovida pelo REUNI, "Programa de Apoio a Planos de Reestruturação e Expansão das Universidades Federais" criado no governo Lula.

O modelo do acoplamento entre pesquisa, pós-graduação e mercado fica cada vez mais explícito. O IV PNPG afirma: "Os índices devem refletir a relevância do conhecimento novo, sua importância no contexto social e o impacto da inovação tecnológica no mundo globalizado e competitivo" (BRASIL, 2004, p. 63). Pouco ou nada se diz sobre a formação e transmissão de valores e conhecimentos, o aporte de contribuições de longo prazo, o acrescentar ao patrimônio cultural e o acúmulo de sabedoria. Toda ênfase é colocada na produção de conhecimento novo, o que mais recentemente ficou consagrado com o conceito de "inovação". Os tempos ideais de integralização foram ainda mais reduzidos, dois anos para o mestrado e 4 para o doutorado, embora esses prazos possam ser flexibilizados em algumas áreas, inclusive na área de História sem que o PPG seja prejudicado na avaliação, o fato é que as parcelas de bolsa e custeio aos programas não foram alterados, $o$ aluno pode levar mais alguns meses, mas sem o financiamento da bolsa. Podemos dizer que, no caso brasileiro, o modelo empresarial de educação presentes em reformas como a de Bolonha (ALMEIDA, 
2008), ao menos no nível de pós-graduação, já estavam em andamento acelerado desde os anos 80 . Os indicadores de produtividade de nossas pós-graduação, como tempo de integralização de cursos, eram bem superiores a sistemas europeus continentais pré-reforma.

O sistema nacional de avaliação da qualidade da pós-graduação é a pedra angular de nosso atual "regime de autonomia" (ARAUJO, 2015). Ele possibilita, caracteriza e limita o que podemos ou não fazer e como o fazemos. Ele se legitima pela ideia da participação dos pares, da comunidade científica, na formulação dos critérios de avaliação. Mas como medir a extensão e profundidade dessa participação? Como garantir que não estamos cada vez mais reféns de gestores afastados das atividades "profissionais" e dos horizontes disciplinares? A presença de docentes-pesquisadores nos órgãos e conselhos superiores é uma forma importante de garantir essa participação profissional, mas é difícil avaliar seu peso efetivo na formatação do SNPG. Além disto, e talvez mais importante, a concepção de ciência e conhecimento que predomina é aquele ditado pelas ciências duras. Agora esse modelo avança para o sistema educacional global, mas para isso precisa desmontar as autonomias profissionais e impor um padrão ultra-simplificado e ultra-econômico de ensino básico que consolida o papel da escola pública como conformadora de um ethos liberal, como instituição amortecedora das inevitáveis tensões sociais provocadas pelo modelo de concentração de renda que sustenta as economias globais. A chamada "sociedade do conhecimento" para as massas se reduz à educação para o consumo, por isso as reformas parecem trabalhar para o rebaixamento das expectativas educacionais em uma retórica que insiste ora na incapacidade do aluno, ora em uma suposta e generalizada má formação do professor (COLE; McKAY, 1999).

Se é verdade que o modelo de ciência imposto pelo SNPG aprofundou a distância entre a história ensinada e a história pesquisada, a solução para essa distância não está em naturalizá-la em nome de uma integração curricular que enfraqueça as disciplinas. A boa interdisciplinaridade é aquela que está assentada em disciplinas fortes. Devemos lutar em todas as frentes para reaproximar esses dois universos, respeitando as autonomias dos diferentes espaços e objetivos da educação histórica, mas reafirmando o acesso às 
condições de produção da história como elemento central da formação humana integral. O enfraquecimento da disciplina histórica pode ser o passo decisivo para o "fim da história", ou a sua aristocratização, permanecendo as massas em uma espécie de tempo vazio ocupado pelos fluxos de consumo. Qualquer reforma do ensino que não promova a aliança entre as disciplinas e os universos educativos servirá apenas para atender as demandas pontuais do nosso consenso global pelo empobrecimento da educação.

Analisando o mesmo fenômeno de outro ângulo, Jurandir Malerba demonstrou como muito do chamado boom da história, um suposto interesse crescente por assuntos históricos, tem sido atendido e promovido pela indústria cultural em obras de baixíssima qualidade, que longe de complexificarem a experiência da história, reduzem-na aos preconceitos e interesses de uma manutenção conservadora do sistema. Portanto, sua observação pode ser transportada para o problema que enfrentamos aqui:

[...] devemos reconhecer que a historiografia acadêmica brasileira ainda tem jogado um papel muito tímido, ao abrir mão da ocupação dos espaços públicos de debate para manter-se confinada nos circuitos fechados da academia (MALERBA, 2014, p. 31).

O que gostaríamos perguntar neste artigo é como o sistema nacional de pós-graduação no Brasil pode se transformar para ajudar a reverter essa situação, que não atinge apenas ou principalmente a área de história, mas é por ela que gostaríamos de abordar a questão.

\section{Um rápido retrato da área de História}

Em 1973 o Brasil tinha 14.500 alunos matriculados em 117 cursos de graduação em história (BRASIL, 1974, p. 155). Para o início de 1975 o I PNPG estimava a oferta de 255 vagas de mestrado e nenhuma de doutorado para a área de História. Em 2012, segundo nosso documento de área, estavam matriculados 5.591 
alunos em cursos de mestrado e doutorado em 62 programas de pós-graduação então existentes. Os dados consolidados do censo do ensino superior indicavam, para o ano de 2005, a existência de 346 cursos de história voltados para a formação de professores e 91 bacharelados, sendo que 37 deles na rede federal. Enquanto existiam 158 licenciaturas sediadas em instituições públicas estaduais, nessas mesmas eram apenas 11 bacharelados. Em 2005 as redes federal e privada (aqui incluídas as comunitárias e filantrópicas com 40 cursos) concentravam mais de 80\% dos bacharelados. Em 2005 esses cursos tinham matriculado 33.190 alunos em licenciaturas e 23.430 em Bacharelado. Do universo de bacharéis, cerca de 50\% (10.878) estavam matriculados na rede federal que, no mesmo ano, tinha 3.762 matriculados em licenciaturas ${ }^{6}$.

Após 4 décadas, a área de história como uma disciplina universitária foi capaz de formar e reproduzir seus quadros em um ambiente institucionalmente homogêneo e, apesar de ainda concentrado regionalmente, esse traço vem progressivamente diminuindo. Mas a pergunta que precisamos fazer é sobre os efeitos dessa novíssima realidade no conhecimento histórico produzido. Podemos apenas levantar algumas hipóteses e perguntas, pois ainda temos poucas pesquisas sobre o tema ou ferramentas estáveis como bancos de dados, mas uma das pedras angulares do modelo, como dito acima, foi o sistema de avaliação construído ao longo dessas décadas sob a liderança e coordenação da Capes.

Segundo o relatório da avaliação trienal 2007-2009, a base Qualis contava com cerca de 1.200 periódicos, no final do triênio seguinte foram avaliados 2.285 itens. Como a área cresceu cerca de $20 \%$ (de 53 para 62 programas), portanto esteve longe de dobrar de tamanho, certamente vivemos uma grande aceleração da produção de artigos. Entre os estratos A1 e B2, segundo o mesmo relatório de 2010, foram classificados 885 artigos, no triênio seguinte esse número mais que dobrou, chegando a 1.726 publicações, como demonstra o quadro seguinte. 
Valdei Lopes de Araujo

\begin{tabular}{|c|c|c|}
\hline 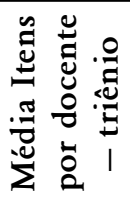 & $\begin{array}{l}\tilde{o} \\
\frac{\tilde{\theta}}{0} \\
\tilde{D} \\
\tilde{\omega}\end{array}$ & $\begin{array}{l}m \\
m \\
n\end{array}$ \\
\hline تี & 竞 $\frac{0}{0}$ & 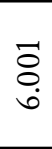 \\
\hline 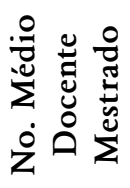 & $\begin{array}{l}\tilde{o} \\
\frac{0}{0} \\
\frac{\pi}{0} \\
\tilde{D}\end{array}$ & $\stackrel{2}{\leftrightarrows}$ \\
\hline 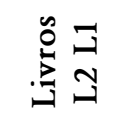 & घี $\frac{0}{\frac{o}{0}}$ & $\underset{\sim}{\stackrel{\infty}{\sim}}$ \\
\hline 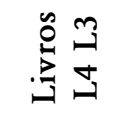 & $\stackrel{\infty}{\stackrel{0}{0}}$ & 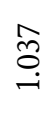 \\
\hline 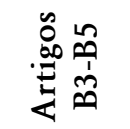 & 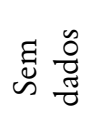 & 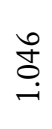 \\
\hline 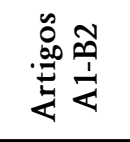 & $\stackrel{\infty}{\infty}$ & 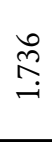 \\
\hline 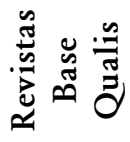 & 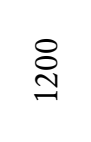 & 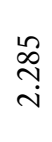 \\
\hline Z & กn & ชె \\
\hline 串 & 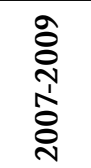 & 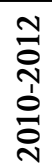 \\
\hline
\end{tabular}

Anos 90, Porto Alegre, v. 23, n. 44, p. 85-110, dez. 2016 
A ênfase em nosso atual sistema de pós-graduação, que se tornou quase que o único ambiente de pesquisa em história, tem sido alta especialização e quantidade de produção, em particular artigos em coletâneas e periódicos. A alta especialização é condição para o rigor e aprofundamento dos campos de investigação, mas também responde melhor à exigência de produção acelerada e contínua. Mas esses produtos acabam por interessar a um número muito reduzido de especialistas, os únicos capazes de alcançar o debate e de ter uso para esses resultados. Fica cada vez mais improvável falar de uma disciplina história como um campo amplo de debate, o que certamente contribui para o enfraquecimento de um ethos profissional. Outro aspecto negativo da especialização é a sua transposição para o sistema de formação, como destacou Carlos Fico, o aluno recebe uma bolsa de Iniciação Científica que tende a definir o tema de suas pesquisas até o doutorado, sendo "[...] cada vez mais frequente a titulação de doutores com pouca experiência profissional (no ensino ou em qualquer outra atividade) e que praticamente só conhecem a temática de sua especialização" (FICO, 2012) ${ }^{8}$.

A exigência de volume de produção não é contrabalançada por mecanismos eficazes de avaliação de qualidade, relevância ou de impacto deste conhecimento produzido e/ou acumulado. A redução do tempo de formação e um modelo de conhecimento focado em projetos de curta duração (alguma vezes um ou dois anos, como pedem os editais ou as dissertações), contribuiu para fragmentar o conhecimento, em especial pelo fato da área não ter aderido a formas mais coletivas de trabalho intelectual, vetando, por exemplo, a coautoria discente-docente. Isso impacta na historiografia no enfraquecimento de um horizonte comum de debate e em sua capacidade de enfrentar problemas de maior complexidade e relevância social.

O modelo da alta especialização torna ainda mais difícil o acoplamento entre "história como pesquisa e prática educacional" e "história como pesquisa profissional" conduzida nas universidades e pós-graduações. Não se trata de simplesmente denunciar um suposto produtivismo, entendido como "excesso" de produção, porém de analisar mais profundamente o sentido dessa produção e o ambiente no qual ela acontece. $\mathrm{O}$ modelo da Capes de não estabelecer metas é insustentável a longo prazo, incentivando 
a competição e não a colaboração entre os programas e legitimando eventuais desinvestimentos. Sabemos que a Capes pode fechar programas que repetidamente recebem a nota mínima de funcionamento. Por outro lado, o MEC não avalia ou cobra produção cientifica de docentes com dedicação exclusiva que estão fora do sistema de pós-graduação, criando as condições para uma carreira que na prática pouco incentiva a pesquisa e, logo, uma formação de excelência?.

Nas ciências de produto (duras) esse modelo é controlado pelo uso e aperfeiçoamento de fatores de impacto e, mais importante, pelos produtos, patentes e processos gerados por esse conhecimento. Com esses elementos elas conseguem produzir um discurso e uma prática sobre sua relevância social. Qual a relevância social da historiografia que possa ser facilmente compreendida por amplas camadas da sociedade? Como regular uma crescente produção intelectual sem os fatores de impacto, seja os internos ao próprio campo, seja aqueles que possam se traduzir em transformações sociais? Como impedir que a educação em história se afaste cada vez mais do universo profissional, correndo o risco de ser controlado pelos horizontes de congelamento do tempo vazio que alimenta o capitalismo global? Por tempo vazio entendo aqui a tradução de toda a diferença histórica pelos valores da subjetividade liberal resultando na incapacidade de pensar e sentir a diferença e o novo como estrutura do tempo histórico, um fenômeno que tem recebido caracterização convergente na tradição crítica do historicismo que passa por autores tão diversos quanto Nietzsche e Benjamin, Heidegger e Derrida, e, na Historiografia, Pierre Nora, Hans-Ulrich Gumbrecht, Hayden White, François Hartog, dentre outros.

Como dito acima, há uma tendência global de desinvestimento do Estado na educação, uma das formas é reduzir ao núcleo "letramento" e "numeramento" (SIC) o universo a que o estado estaria obrigado a ensinar. Isso também vai ao encontro de um ensino superior reorganizado em torno de problemas econômicos, e não disciplinares, modelo celebrado pelo aprendizado por competências. Em artigo recente sobre os impactos do modelo de avaliações empresariais no contexto europeu, o historiador holandês Chris Lorenz argumenta que estas práticas enfraquecem o universo profissional 
da atividade do historiador (LORENZ, 2014). Segundo Lorenz, profissionalismo exige autonomia intelectual. A avaliação em bases quantificáveis, no caso específico de seu artigo fundadas em fatores de impacto, destruiria paulatinamente essa autonomia ao serem usadas por gestores profissionais afinados com as agendas econômicas e um modelo de gestão por metas externamente determinadas. A quantificação e a ideologia do crescimento tornam-se, no novo regime intelectual, o maior obstáculo à autonomia, mas como essa última não pode ser entendida de modo absoluto, podemos afirmar que vivemos uma disputa, devemos pensar como preservar a autonomia intelectual e profissional neste novo ambiente hostil. Para o sociólogo Chistian Fleck, em artigo publicado em 2013, em que estuda os fatores de impacto, "The procedures for calculating the impact factor are inappropriate. Despite its obvious unsuitability, the impact factor is used by editors of sociological journals [...]" (FLECK, 2013, p. 1).

Em horizonte global o enfraquecimento das disciplinas com bases profissionais tem sido a plataforma para a precarização do trabalho docente em todos os níveis, como destaca Lorenz. Essa realidade no Brasil se traduz no sobretrabalho e em uma carreira docente que não reflete de modo adequado as múltiplas responsabilidades do docente-pesquisador. Tanto porque a atividade de pesquisa é sobre-avaliada e sub-financiada, quanto porque a dimensão do ensino e da extensão não são suficientemente pensadas, acompanhadas e dimensionadas nos encargos docentes. Da mesma forma é muito comum que os parâmetros de progressão construídos por cada IFES, em função de pressões corporativas, não reconheçam o esforço de pesquisa e a atuação na pós-graduação. A flexibilização das regras de progressão na carreira permite que um docente chegue ao topo, ao cargo de titular, sem produção científica relevante.

O modelo do SNPG afirmou a universidade como local privilegiado da pesquisa, sem que a carreira docente fosse suficientemente reestruturada. Mas o fato é que ser pesquisador no Brasil significa ser "docente" do ensino superior, e ser docente significa atuar em inúmeras atividades além da pesquisa. Se há um ethos do jovem pesquisador, ele está mais ligado ao modelo pesquisadordocente e cada vez menos a um "horizonte profissional" ditado 
pelas disciplinas tradicionais e avaliação substantivas de qualidade do conhecimento produzido. Isso enfraquece e torna mais genérico o controle profissional do conhecimento, ele passa a ser regulado pelo sistema da Pós-Graduação e pelas políticas de financiamento das agências de pesquisa. Não parece ser acidental, que estas agências estejam mais voltados para um projeto de ciência acoplado às demandas econômicas. Nesse sistema, a avaliação substantiva é transferida para a capacidade desse conhecimento gerar tecnologia, inovação e riqueza. Esse círculo se fechará quando o financiamento vier diretamente dos setores produtivos, a exemplo do modelo anglo-americano do pesquisador-empresário, ou, no caso brasileiro, dos editais induzidos. O exemplo mais recente e sintomático desse processo foi a exclusão das humanidades de um programa da envergadura do Ciências Sem Fronteiras.

Precisamos reafirmar a universalidade do conhecimento como um direito humano e reagir à linguagem empresarial que transforma a educação em uma commodity global, isso sem abdicar da busca pela qualidade e da avaliação, mas estas precisam ser definidas a partir de um horizonte profissional. Os sindicatos são importantes, mas não podem substituir o papel central que deve ter instituições profissionais como a Anpuh, cuja agenda pode e deve ir além da dimensão corporativa, em especial no momento em que estamos prestes a criar a profissão de historiador. $\mathrm{Na}$ formulação de Chris Lorenz, em texto de 2009 em que se pergunta se as universidades sobreviveriam à integração europeia:

[...] a economia capitalista já não encontra sua legitimação ideológica em termos científicos, como foi o caso do 'capitalismo tardio' [...], porque a ciência agora tem que justificar a si mesma em termos econômicos (LORENZ, 2009, p. 54).

O exemplo de Portugal é bem revelador do risco das reformas empresariais, como resume Luciano Almeida, em função do acordo de Bolonha, que deveria ser implantado até 2010, em 2007 o governo encomendou um relatório sobre o sistema educacional a uma das agências de controle da União Europeia. O relatório foi muito duro e sugeriu diversas reformas de governança, inclusive 
O regime de autonomia avaliativo no Sistema Nacional de Pós-Graduação...

ações polêmicas como mudanças profundas nos estatutos, como fim de eleição geral de reitores, participação de 20\% de membros da comunidade externa nos conselhos deliberativos, mudança da natureza jurídica da universidade, dentre outra medidas. Em quatro meses o governo passou leis aprovando a maior parte das sugestões, a despeito das fortes reações corporativas. As instituições tiveram 8 meses para reescreverem seus estatutos em adequação à nova legislação (ALMEIDA, 2008, p. 598-601).

Essa realidade é ainda diferenciada nos sistemas universitários europeus, em países como a Grã-Bretanha e Holanda as políticas liberalizantes avançam profundamente na precarização das condições docentes. Os profissionais têm cada vez menos oportunidades de obterem empregos em que a estabilidade seja uma opção, promovendo uma constante migração entre vagas provisórias, os níveis de produtividade e competição tornam quase uma obrigação o uso de horas não remuneradas para o desenvolvimento de atividades laborais, realidade que também parece se naturalizar como ethos do pesquisador no Brasil. O encurtamento dos prazos de execução e a exigência de constante renovação dos projetos de pesquisa fragmenta de modo artificial os resultados da investigação. Um elemento positivo desse cenário sombrio parece ser o maior envolvimento desses jovens pesquisadores com organizações sociais (IVANCHEVA, 2015, p. 42-46).

Para o Historiador o modelo de avaliação consolidado pela Capes - apesar dos importantes avanços que área tem conseguido e que não podem ser subestimados - significa escrever mais artigos especializados em periódicos e capítulos de coletâneas, do que livros autorais e pesquisas monográficas. Também significa dedicar menos esforço ao ensino (dimensão subavaliada no atual modelo) e mais à pesquisa. Sobra pouco tempo e energia de pesquisadores e programas para a comunicação social do conhecimento, a difusão histórica e mesmo o universo didático, que ainda não encontrou reconhecimento efetivo na atual matriz, assim como os produtos da pesquisa continuam limitados ao texto escrito, sem considerar as novas mídias e formatos atualmente disponíveis. Como apontou estudo recente de Jaime Guinzburg, 
[...] a mesma comunidade acadêmica que trabalha com dedicação por suas revistas não as cita com a frequência esperada. É possível perguntar então: para quem os pesquisadores estão escrevendo? (GINZBURG, 2014).

Como não há medição do impacto dos textos, continuamos a gastar mais energia em produzí-los do que em divulgá-los. Embora a área de história não considere os fatores de impacto na avaliação de seus periódicos, esses dados estão disponíveis para a Capes. Assim, com base na produção de artigos de pesquisadores ligados à cursos de doutorado, a área de história teria publicado 284 artigos em periódicos internacionais, representando 1,1\% da produção global, mas com o impacto de apenas 0,2. Os números são um pouco melhores para algumas áreas afins, Educação 1,3 para 0,7; Sociologia 0,6 para 0,7; Ciência Política 0,7 para 0,6 e Antropologia 1,2 para 2,8 (AVELLAR, 2010, p. 80 et seq.).

O empoderamento contínuo da dimensão disciplinar da historiografia passa por assumir como parte da nossas tarefas "profissionais" a pesquisa e reflexão contínua sobre o "Estado do Campo" em todas as suas dimensões: formação (em nível de graduação e pós-graduação), ensino (fundamental e médio), produção, comunicação e difusão do conhecimento acumulado. Fazer isso significa deslocar o debate e a prática sobre avaliação das esferas estatais e burocráticas para âmbitos mais sensíveis à autonomia profissional. Acreditamos que os historiadores precisam assumir individual e coletivamente a tarefa de comunicar (inclusive didaticamente) e defender a relevância social de sua atividade, mas para isso é preciso que este esforço seja reconhecido nas avaliações em diferentes níveis (BARROS, 2007). Da mesma forma, precisamos refundar a aliança entre a "educação para a história" e a "história pesquisada" produzida em horizontes profissionais, como destaca Carlos Barros,

El elemento decisivo del espacio público de la historia, son las escuelas: en ningún otro lugar es más conveniente que el profesor de historia actúe como un historiador público, comprometido con la tarea de hacer de los alumnos parte activa del sujeto de la historia que se aprende y que se hace (BARROS, 2007, p. 14).

Anos 90, Porto Alegre, v. 23, n. 44, p. 85-110, dez. 2016 
O regime de autonomia avaliativo no Sistema Nacional de Pós-Graduação...

Isso sem esquecermos que a educação para a história entendida como realização da humanidade em sua integralidade também não pode se limitar ao espaço escolar. O historiador deve atuar em todos os outros espaços e instituições onde o discurso e a representação histórica estejam em jogo.

Para concluir de modo propositivo, listo algumas ações que poderiam contribuir para esse (re)empoderamento da historiografia como disciplina e da história como direito fundamental cujas condições de efetivação devem ser universalizadas.

\section{Ações estruturantes}

1. Fortalecer e qualificar as Anpuhs como espaço de debate e ação a favor da História como campo disciplinar, escolar e profissional.

2. Criar mecanismos permanentes de subsídio à área de história na Capes de modo a potencializar nossa capacidade de interferir no SNPG, em especial na construção de um modelo avaliativo mais transparente e sensível aquilo que a área imagina que deva ser a função e o ethos da pesquisa em história e nas humanidades. Precisamos construir pesquisas e ferramentas de diagnóstico do campo em diversas frentes: a) sistema escolar; b) ensino de graduação e formação de professores; c) pesquisa e pós-graduação. Qual a evolução do número de vagas, de formandos, o crescimento da comunidade historiadora e suas tendências? Nesse sentido, seria oportuna a criação, no âmbito da Anpuh, de um Laboratório Nacional de Referência da Pesquisa, Ensino e Difusão em História, multicêntrico e pluri-institucional.

3. Produzir metodologias de mensuração da educação histórica e trabalhar para que exames como o IDEB incorporem as dimensões da "educação histórica" em suas avaliações. 


\section{Ações pontuais}

1. Tornar o livro autoral o produto mais importante e de maior peso na avaliação dos PPGs. Paralelamente, construir políticas de democratização de acesso ao livro, com a indução do acesso livre como política da área e o fortalecimento das editoras universitárias como principal veículo para produção desses livros.

2. Valorizar e incentivar a produção didática como produção científica.

3. Valorizar e incentivar ações de "comunicação" e difusão do conhecimento histórico produzido, com particular atenção ao uso de novas medias. $\mathrm{O}$ pesquisador individual deve cada vez mais se responsabilizar pela "comunicação social” de sua pesquisa, mas deve ser estimulado a fazê-lo e premiado nas avaliações.

4. Atuar para que o modelo vigente de avaliação construa ferramentas mais transparentes e sensíveis à qualidade julgada a partir de critérios profissionais (aperfeiçoamento da avaliação de periódicos, livros e demais produtos).

5. Apoiar iniciativas como as Olimpíadas de História e grandes eventos voltados para o público não especializado, a exemplo do "Festival de História".

6. Apostar em políticas que levem a uma maior integração dos programas de pós-graduação. Atuar junto a Capes para que aperfeiçoe e incentive os programas em rede, a exemplo do ProfHis, também para os programas acadêmicos. A fragmentação dos programas tem feito que a relação entre eles seja mais competitiva do que colaborativa.

7. É preciso ampliar o debate sobre novos formatos para os nosso cursos de graduação e pós-graduação. Há pouca variedade e pouca reflexão sobre como atingir um público 
O regime de autonomia avaliativo no Sistema Nacional de Pós-Graduação...

não necessariamente preocupado com a construção de uma carreira docente na área.

8. Atuar politicamente e produzir alternativas para a matriz de avaliação Capes e sua ênfase na competição incessante entre áreas e programas e na ausência de metas limitadas de produção cientifica. É preciso romper com a lógica do quanto mais melhor e assumir maior responsabilidade pela distribuição da energia do docente-pesquisador e dos PPG.

\section{THE EVALUATIVE AUTONOMY REGIME IN THE NATIONAL POST- GRADUATE SYSTEM AND THE FUTURE OF RELATIONS BETWEEN HISTORIOGRAPHY, LEARNING AND HISTORY EXPERIENCE}

Abstract: This article analyzes how the accommodation of historiography in a regime of autonomy marked by evaluative models drives this field away from its disciplinary origins in the 19th century and the professional development of the 20th century. I call regime of autonomy the arrangement of forces that enables a given discourse to acquire individuality and be differentiated in the web of enunciations available at a specific time and place. A "regime" is a way to describe how interactions of these forces enable, affect and shape historical discourse, especially the relationship between the vectors author-producer, reader, circulation, consumption, languages, concepts and media. The hypothesis developed here is that an "evaluative regime of autonomy", common to other areas of contemporary science, is changing historiography, celebrating a highly specialized profile, threatening the relevance and social communicability, endangering professional ability of contributing to the diversification of historical experience.

Keywords: Sistema Nacional de Pós-Graduação. Historiography. Regime of evaluative autonomy. History teaching.

\section{Notas}

${ }^{1}$ Esse texto foi produzido para o debate promovido pela Anpuh em 13 de maio de 2015 acerca das reformas do ensino médio e o futuro das Humanidades. Além de ter sido enriquecido com sugestões do debate, muito deve ao diálogo com os colegas do NEHM-UFOP, em especial Marcelo Abreu, Marcelo Rangel, Helena Mollo e Mateus Pereira. Também foi apresentado no ciclo de debates "A história 
(in)disciplinada”, agradeço a Arthur Lima, Fernando Nicolazzi, Temístocles Cezar e outro colegas do departamento de história da UFRGS pela oportunidade. Essa pesquisa conta com o apoio do CNPq, Capes, Fapemig e UFOP.

2 Para um panorama das iniciativas estatais visando regular os conteúdos históricos ensinados, nesse caso através de políticas para o livro didático, ver Oliveira \& Franco (2013).

${ }^{3}$ Só assim que poderíamos realizar os deslocamentos e ampliações do escopo da educação histórica, tão necessários como contraponto a sua tendência ao congelamento, esses descentramentos "[...] permitem ainda relativizar a própria razão histórica fundada na produção de sentido, abrindo espaço para outras formas críticas do mundo igualmente potentes ainda que não controladas pelos protocolos científicos”. Por isso que uma educação para a diversidade e a democracia, muito mais que um elogio neo-positivista da empiricidade, requer um esforço teórico contínuo (ABREU; RANGEL, 2015, p. 19).

${ }^{4}$ Sobre os efeitos da exterioridade das ferramentas avaliativas no processo de Bolonha, ver Silva (2013).

${ }^{5}$ Essas observações críticas não devem ser universalizadas, sabemos da importância estratégica do investimento em CT\&I e de como esse modelo tem contribuído para o seu desenvolvimento, o que devemos pensar é se ele atende adequadamente às especificidades das diferentes áreas das humanidades e que em direções ele deveria continuar a ser adaptado. Para uma visão geral e, de certo modo, "oficial" da evolução da pós-graduação, ver Avellar (2010).

${ }^{6}$ Essas informações foram retiradas diretamente das tabelas disponíveis no INEP. Estão sujeitas a revisão e atualização.

${ }^{7}$ Agradeço a Rebeca Gontijo sugestões e correções a uma primeira versão dessa tabela debatida.

${ }^{8}$ Em sua postagem no blog Brasil Recente Carlos Fico traz importantes elementos críticos a esse debate, argumentando contra o diagnóstico genérico de produtivismo frequentemente levantado por setores descontentes com o modelo Capes (FICO, 2012). Embora concorde com o argumento de que essa produção é ainda irregularmente distribuída, a tendência do modelo é homogeneizar um perfil de excelência ligado a um crescente número de publicações, sem um teto que regule esse crescimento ou uma avaliação mais holística da carreira docente. Um professor muito produtivo pode precarizar outras dimensões de sua atividade docente, como o ensino, a formação, a extensão ou a gestão acadêmica. Não há solução simples para esses problemas, mas precisamos de mais diagnósticos e bases de dados integrativas e confiáveis que possam gerar indicadores mais transparentes e séries históricas estáveis.

${ }^{9}$ No sistema como um todo, incluindo as redes privadas e estaduais, apenas 18\% dos docentes estavam envolvidos com a Pós-Graduação em 2009 (AVELLAR, 2010, p. 54).

Anos 90, Porto Alegre, v. 23, n. 44, p. 85-110, dez. 2016 
O regime de autonomia avaliativo no Sistema Nacional de Pós-Graduação...

\section{Referências}

ABREU, M.; RANGEL, M. Memória, cultura histórica e ensino de história no mundo contemporâneo. História e Cultura, Franca, v. 4, n. 2, p. 7-24, 2015. ALMEIDA, L. S. R. de. Evolução do sistema de ensino superior após a revolução de abril de 1974: Expansão e desregulação. 2008. Tese (Doutorado em Educação)-Universidad de Extremadura, Badajoz, 2008.

ARAUJO, V. L. de. Historiografia, nação e os regimes de autonomia na vida letrada no Império do Brasil. Varia Historia, Belo Horizonte, v. 31, n. 56, p. 365-400, maio/ago. 2015.

BARROS, C. Propuestas para el nuevo paradigma educativo de la historia. Revista HISTEDBR Online, Campinas, n. 28, p. 2-24, dez. 2007.

. Histografía de valores. In: CONGRESO INTERNACIONAL HISTORIA A DEBATE, 4., 16 dic. 2010, Santiago de Compostela. Ampliado en mayo 2014. Disponível em: <https://www.academia.edu/7064229/Historiograf\%C3\%ADa_de_valores>. Acesso em: 24 jul. 2016.

BRASIL. Ministério da Educação e Cultura. Conselho Nacional de Pós-Graduação. Departamento de Documentação e Divulgação. I PNPG - Plano Nacional de Pós-Graduação. Brasília, DF: MEC, 1974.

. Ministério da Educação e Cultura. Secretaria de Educação Superior. Coordenação de Aperfeiçoamento Pessoal de Nível Superior. II PNPG - Plano Nacional de Pós-Graduação (1982-1985). Brasília, DF: CAPES, 1981.

. Ministério da Educação e Cultura. Secretaria de Educação Superior. Coordenação de Aperfeiçoamento Pessoal de Nível Superior. III PNPG - Plano Nacional de Pós-Graduação (1986-1989). Brasília, DF: CAPES, 1985.

. Ministério da Educação. Coordenação de Aperfeiçoamento Pessoal de Nível Superior. Plano Nacional de Pós-Graduação (PNPG) 2005-2010. Brasília, DF: CAPES, 2004.

CARRETERO, M.; ALPHEN, F. van. Do Master Narratives Change Among High School Students? A Characterization of How National History Is Represented. Cognition and Instruction, v. 32, n. 3, p. 290-312, 2014.

CERRI, L. F. Cartografias Temporais: metodologias de pesquisa da consciência histórica. Educação e Realidade, Porto Alegre, v. 36, n. 1, p. 59-81, 2011.

COLE, J.; McKAY, I. Organized Lightning: the Liberal Arts against neoliberalism. Our Schools/Our Selves, Ottawa, v. 24, n. 2, \#118, p. 123-137, Winter 2015. 
FICO, C. Avaliação da pós-graduação: produtivismo? Brasil Recente, 13 jul. 2012. Disponível em: 〈http://www.brasilrecente.com/search?q=produtivismo〉. Acesso em: 24 jul. 2016.

FLECK, C. The Impact Factor Fetishism. European Journal of Sociology, v. 54, n. 2, p. 327-356, 2013.

GINZBURG, J. Periódicos acadêmicos: antagonismo entre produção e leitura (notas sobre revistas da área de Letras publicadas em 2013). Revista Expedições: Teoria da História \& Historiografia, Morrinhos, GO, v. 5, n. 1, p. 10-41, 2014.

GUIMARÃES, J.; AVELLAR, S. O. C. CT \& I no Brasil: um balanço da capacitação e desempenho atual do sistema de pós-graduação e de pesquisa. Parcerias Estratégicas, Brasília, DF, v. 15, n. 31, p. 53-84, jul./dez. 2010. Edição especial. HERNÁNDEZ, G. D. M.; PAZ, R. O. La enseñanza del "tiempo histórico": problemas y propuestas didácticas. História \& Ensino, Londrina, v. 19, n. 1, p. 29-47, jan./jun. 2013.

IVANCHEVA, M. The age of precarity and the new challenges to the academic profession. Studia UBB Europaea, Cluj-Napoca, v. 60, n. 1, p. 39-47, 2015.

LEWKOWICZ, M.; RODRIGUEZ, M. Historiografía académica e historia escolar: los libros de texto de historia entre dos centenarios. História da Historiografia, Ouro Preto, n. 20, p. 48-68, abr. 2016.

LORENZ, C. F. C. Sobrevivirán las universidades a la integración europea? Políticas de educación superior en la UE y en los Países Bajos antes y después de la Declaración de Bolonia. Reencuentro, México, D.F., n. 54, p. 53-71, abr. 2009.

. Fixing the facts: the rise of nnew public management, the metrification of "quality" and the fall of the academic professions. Moving the Social-Journal of Social History and the History of Social Movements, Bochum, v. 52, n. 4, p. 5-26, 2014.

MALERBA, J. Acadêmicos na berlinda ou como cada um escreve a História?: uma reflexão sobre o embate entre historiadores acadêmicos e não acadêmicos no Brasil à luz dos debates sobre Public History. História da Historiografia, Ouro Preto, n. 15, p. 27-50, ago. 2014.

OLIVEIRA, M. M. D. de; FRANCO, I. Historiografia didática e prescrições estatais sobre conteúdos históricos em nível nacional (1938-2012). Revista Territórios \& Fronteiras, Cuiabá, v. 6, n. 3, p. 6-24, dez. 2013.

PALACIOS, P. C. L. Luhmann: Exámen de sus ideas el oficio del historiador. Historia y Grafía, México, D.F., n. 39, p. 125-145, jul./dec. 2012. 
O regime de autonomia avaliativo no Sistema Nacional de Pós-Graduação...

PEREIRA, M. H. de F. Nova direita? Guerras de memória em tempos de Comissão da Verdade (2012-2014). Varia Historia, Belo Horizonte, v. 31, n. 57, p. 853-902, set./dez. 2015.

PIMENTA, J. P. G. et al. A Independência e uma cultura de história no Brasil. Almanack, Guarulhos, n. 8, p. 5-36, 2. sem. 2014.

SCHMIDT, B. B. De quanta memória precisa uma democracia? Uma reflexão sobre as relações entre práticas memoriais e práticas democráticas. Anos 90, Porto Alegre, v. 22, n. 42, p. 153-177, dez. 2015.

SILVA, L. L. A formação de formadores no contexto da transnacionalização educativa: reflexões a partir da aplicação do processo de Bolonha em Espanha e Portugal. Educação e Sociedade, Campinas, v. 34, n. 122, p. 247-263, jan./ mar. 2013.

Recebido em: 01/07/2016

Aprovado em: 30/09/2016 